\title{
Effect of homeownership on the utilization of local public health services among rural migrants in China: a nationwide cross-sectional study
}

\section{Zicheng Wang}

Jinan university

Jiachun Liu

Jinan university

Juan Ming ( $\square$ mingjuan520888@gdut.edu.cn )

Guangdong University of Technology https://orcid.org/0000-0002-2677-3402

\section{Research}

Keywords: Homeownership, Utilization of local public health services ,Establishment of health record, Attendance of health education, Demand-side determinants, Supply-side barriers

Posted Date: March 18th, 2020

DOl: https://doi.org/10.21203/rs.3.rs-17907/v1

License: (c) (i) This work is licensed under a Creative Commons Attribution 4.0 International License. Read Full License 


\section{Abstract}

Background: Rural-urban migrants often suffer overrepresented health risks but have less access to public health services $₫$ while the homeownership status in China may play a vital role in the attainment of local welfare. However, the effect of homeownership on the public health services utilization is still understood. This study aims to address the causal effect of homeownership on the utilization of local public health services among rural migrants in China. Three issues are addressed to discuss: Whether the homeownership produces a significant effect on the utilization of local public health services or not? Are there any interaction effect between homeownership and location of household/ healthcare center? Does the homeownership effect vary by employment status, migration duration and migration patterns?

Methods: The dataset from the 2017 National Migrants Population Dynamic Monitoring Survey (NMPDMS-2017) is applied to explore the direct effect of homeownership on the utilization of local public health services. The Logit regression is conducted to discuss the associations, while the IV estimation developed by Lewbel (2012) is employed to correct the endogeneity of homeownership. Additionally, the Logit regressions are also performed to explore the interaction effect and heterogeneous effect.

Results: The Logit estimations reveal that the homeownership is positive with the establishment of health record (OR=1.1926; $95 \% \mathrm{Cl}=1.154,1.2325)$ and the attendance of health education (OR=1.1883; $95 \%$ $\mathrm{Cl}=1.1506,1.2271$, while IV estimations also confirms that the homeownership has a positive effect on the establishment of health record (Coefficient $=0.0222 ; 95 \% \mathrm{Cl}=0.0121,0.0323$ ) and the health education access (Coefficient $=0.0241 ; 95 \% \mathrm{Cl}=0.0139,0.0343$ ). The interaction term of homeownership and household location (Coefficient $=1.4141 ; 95 \% \mathrm{Cl}=1.2453,1.6057$ ) as well as the interaction between homeownership and healthcare center location (Coefficient $=1.1476 ; 95 \% \mathrm{Cl}=1.0491,1.2554$ ) are related with the increased establishment of health record establishment, whereas only the interaction of homeownership and household location shows significant correlations in the health education model(Coefficient $=1.2186 ; 95 \% \mathrm{Cl}=1.0734,1.3794)$.

Conclusion: The homeownership produces a positive effect on the utilization of local public health services among rural migrants in China. Moreover, the homeownership may play a greater role along with the geographical accessibility.

\section{Background}

China has experienced a massive internal migration since 1978.About 288 million rural migrants serve as industrial workers in destination cities in 2018, and they have become an indispensable part of the urban labor force and an inalienable component of China's urbanization [1]. With the constraint of Hukou system, rural migrants can merely migrate to urban cities for work but have less access to settle down permanently [2-3]. Moreover, the temporary status put them be marginalized in destination cities[4-5], they are often treated as the cheap labor to substitute urban citizens for undertaking the unwilling indecent jobs but share no equal rights with the local citizens. Meanwhile, rural-urban migrants are often 
exposed to overrepresented health risks, including communicable diseases (especially tuberculosis and sexually transmitted diseases), non-communicable chronic diseases and risk factors, workplace injury and occupational health, mental health and women's health [6]. However, they are still regarded as the outsider in terms of the access to the local welfare system [7], and most of them have limited access to urban public healthcare[8-9].

The serious health risks of rural migrants have become one of the most concerned issues in the process of new-urbanization in China [10], and the public healthcare system is almost universally accepted as the important actor to enhance the health status of migrants [11]. In 2009, the central government launched a project named essential public health services (EPHS) to provide basic health services for all urban and rural dwellers [12-13].This project consists of nine types of basic services, including the establishment of health records, health education, health services for children aged 0 to 36 months, maternal health services, elder health services, immunizations, infectious disease reporting and treatment, services for patients with type II diabetes and services for patients with severe mental illness [14-17].

Unfortunately, rural migrants are still less likely to utilize the basic public health services than comparable local citizens [8][16].Previous studies have discussed the determinants of public healthcare utilization both from the supply-side and demand-side. In terms of supply-side, it is confirmed that demographic and socioeconomic factors are major determinants[18-19], and the prevalence of healthcare utilization is differentiated by gender, education attainment, employment status, migration duration, health status and so on $[16,18,20-21]$. Regarding the demand side, the evidences demonstrate that geographical access (distance) is a main barrier to access the healthcare services [15].

However, those studies contribute less to the effect of homeownership on the public healthcare utilization. The homeownership is widely perceived as the crucial milestone of assimilation process, while owning a house represents the long-term commitment to settle down permanently and become a member of the local society [22-23]. Thus, the homeownership may determinate the access to neighborhoods with better physical and social conditions [24-25], and then influence the utilization of local public health services. This is especially the case in China, rural migrants often experience poor living conditions and are less likely to be homeowner [26-27], whereas homeownership not only acted as the pre-condition for their attainment of membership in major cites, but also was the first step to obtain the local welfare benefits, such as education, health care, welfare provision and so on [28-29].

To address this gap, the current study employs a unique national survey in China to further explore the causal effect of homeownership on the utilization of local public health services. Three issues are addressed as follows: (1) whether the homeownership produces a significant effect on the utilization of local public health services or not? (2) Are there any interaction effects between the homeownership and the location of household /healthcare center on the access to public health services? (3) Does the homeownership effect vary by employment status, migration duration and migration patterns?

This research contributes to the literature in two distinct ways. First, the present study addresses demandside and supply-side barriers to the local health services utilization concurrently, and it also emphasizes 
the direct role of homeownership. Second, this study firstly explores the causal effect of homeownership on local public health services utilization in China context, the instrumental variables estimation using heteroskedasticity-based instruments is applied to correct the potential endogeneity, while the employment status and migration traits differentials are further addressed to explore the heterogeneity effect.

\section{Materials And Methods}

\section{Data sources}

We use data from the 2017 National Migrants Population Dynamic Monitoring Survey (NMPDMS-2017) conducted by the National Health and Family Planning Commission of China. NMPDMS-2017 is an open access and a national representative cross-sectional survey of internal migrants aged 15-69 years. These migrants do not have the local "Hukou" and have been living in local cities for more than one month. The survey was conducted in 32 provincial units which covered all 31 provinces and XPCC (Xinjiang Production and Construction Corps) of China, 348 cities and 8450 communities or villages. The distribution of households surveyed across provincial units ranges from 2,000 to 10,000, including seven sampling units , 2000, 4000, 5000, 6000, 7000, 8000 and 10000. 2000 households were sampled from the least populous unit XPCC, and 10000 households were sampled from the largest units such as Zhejiang province and Guangdong province. Those samples were drawn using the stratified multistage random sampling method with the probability proportional to size approach (PPS).

\section{Variables and measures}

The dependent variable is the utilization of local public health services, which is specified as the establishment of health record and health education access, two popular forms of essential public health services. Both those two outcomes are binary variables, while a respondent was coded as 1 if he/she enrolled in the local health information record system, and 0 otherwise. The survey incorporates all of five main items of health education, including education of chronic disease prevention, mental health, infectious diseases, reproductive health and occupational disease. Thus, the dummy of health education attendance is set equal to 1 if rural migrants attended one of the five items at least, while rural migrants did not attend any of the five items is set to 0 .

According to Kiwanuka (2008)[30] , controlled variables are chose according to the demand-side and supply-side barriers concurrently. In the demand-side, the demographic characteristics (gender, age and marital status), health status (whether suffered from chronic disease or not), and the intention of permanent settlement are incorporated. The household location (urban residential community vs village) and healthcare center location (whether the commuting time to the nearest healthcare center was less than 15 minutes or not) are included as the demand-side factors.

\section{Estimation strategy}


All analyses are conducted using the Stata 15.0. The Pearson chi-square tests and ANOVA tests are applied for the univariate analysis. The Logit regression model is performed to explore the direct association between homeownership and the utilization of local public health services, while the interaction effects and heterogeneous effects are also discussed through Multivariate Logit regression .

To address the endogeneity of homeownership, the instrumental variables regression using heteroskedasticity-based instruments to explore the causal effect of homeownership on the local public health services utilization.

\section{Results}

\section{Baseline characteristics}

Table 1 presents the descriptive statistics of dependant variables and controls. About one-fourth ( $26.09 \%$ ) of rural migrants established the health record, and $60.85 \%$ of respondents participated in the health education. Rural migrants are less likely to be homeowner, only $17.32 \%$ of them own a house in local cities.

Among 132,555 respondents, $68,916(51.99 \%)$ are males, and $84.84 \%$ of them are married with the average age of about 36 years old. Approximately one-fifth of rural migrants have less education attainments than the primarily school, which implies that most of them have completed the nine-year compulsory education. About $5.09 \%$ of rural migrants report suffering chronic disease in the last year, while $81.38 \%$ of them would like to settle down permanently. As for the household and healthcare center location, it is shown that only $29.88 \%$ of rural migrants live in the urban residential community, and $83.41 \%$ of them spent less than 15 minutes commuting to the nearest healthcare center.

\section{Univariate analysis}

The Chi-square tests and ANOVA tests in the Table 1 also indicate that the homeownership prevalence among rural migrants with health record is higher than the counterparts (21.22\%vs $15.94 \%)$, while the homeownership rate among health education participants is also higher than the non-participants (19.47\% vs13.96\%). The attendants of health record establishment and health education are less male (health records establishment: $49.59 \%$ vs $52.84 \%$; health education access: $49.84 \%$ vs $55.34 \%$ ) and more married (health records establishment: $88.26 \%$ vs $83.63 \%$; health education access: $87.72 \%$ vs $80.35 \%$ ). The migrants gained the access to local public health services are more educated, while more of them get the education attainment of senior middle school (health records establishment: $21.30 \%$ vs $20.32 \%$; health education access: $21.73 \%$ vs $18.78 \%$ ) and college (health records establishment: $12.33 \%$ vs $10.66 \%$; health education access: $11.86 \%$ vs $9.90 \%$ ). The beneficiaries of public health services usually have more prone to settle permanently (health records establishment: $85.36 \%$ vs $79.97 \%$; health education access: $83.19 \%$ vs $78.56 \%$ ). Additionally, the participants of public health services are more likely to live in the urban residential community (health record establishment:74.77\% vs $68.48 \%$; health 
education access: $73.27 \%$ vs $65.22 \%$ ) and go to the nearest healthcare center for less than 15 minutes (health record establishment: $85.40 \%$ vs $82.72 \%$; health education access: $83.97 \%$ vs $82.56 \%$ ).

\section{Multivariate Logit analysis}

Logit regression is applied to identify the association of homeownership with the utilization of local public health services, from which odd ratios and 95\% confidence intervals $(\mathrm{Cl})$ are calculated.

As shown in the health record model(Table 2), Logit estimations reveal that homeownership (OR=1.1926; $95 \% \mathrm{Cl}=1.154,1.2325)$, gender $(\mathrm{OR}=1.1390 ; 95 \% \mathrm{Cl}=1.1107,1.1682)$, age (OR=1.0027; $95 \%$

$\mathrm{Cl}=1.0013,1.0042)$, marital status $(\mathrm{OR}=1.4199 ; 95 \% \mathrm{Cl}=1.3623,1.4798)$, education attainments (junior middle school, $\mathrm{OR}=1.1321 ; 95 \% \mathrm{Cl}=1.0925,1.1732$; senior middle school, $\mathrm{OR}=1.2085 ; 95 \% \mathrm{Cl}=1.1578$, 1.2614; College or above, $\mathrm{OR}=1.3241 ; 95 \% \mathrm{Cl}=1.2579,1.3938)$, health status(OR=1.1101; $95 \% \mathrm{Cl}=1.0484$, $1,1754)$, permanent settlement intention $(\mathrm{OR}=1.3617 ; \mathrm{Cl}=1.31601 .4090)$, household location $(\mathrm{OR}=1.2694$ $; 95 \% \mathrm{Cl}=1.2330,1.3068)$ and healthcare center location(OR=1.1898; $95 \% \mathrm{Cl}=1.1494,1.2315)$ are related with the increasing prevalence of health records establishment. In the health education model, the participation in health education is positive associated with homeownership (OR=1.1883; $95 \% \mathrm{Cl}=1.1506$, 1.2271), gender $(\mathrm{OR}=1.2112 ; 95 \% \mathrm{Cl}=1.1837,1.2393)$, marital status $(\mathrm{OR}=2.0475 ; 95 \% \mathrm{Cl}=1.9760$, 2.1217), education attainments (junior middle school $\mathrm{OR}=1.2606 ; 95 \% \mathrm{Cl}=1.2219,1.3005$; senior middle school $\mathrm{OR}=1.4693 ; 95 \% \mathrm{Cl}=1.4138,1.5270$; college or above $\mathrm{OR}=1.5065 ; 95 \% \mathrm{Cl}=1.4372,1.5792$ ), permanent settlement intention ( $O R=1.2203 ; 95 \% \mathrm{Cl}=1.1859,1.2558)$, household location (OR=1.3608; $95 \% \mathrm{Cl}=1.3271,1.3953)$ and healthcare center location( $\mathrm{OR}=1.0571 ; 95 \% \mathrm{Cl}=1.0267,1.0895)$, while age $(\mathrm{OR}=0.9926 ; 95 \% \mathrm{Cl}=0.9913,0.9940)$ and health status $(\mathrm{OR}=0.9297 ; 95 \% \mathrm{Cl}=0.8822,0.9798)$ is related with the reduced access of health education.

\section{Causal effect analysis}

The effect of homeownership on the utilization of local public health services may be biased in Logit estimation due to the non-random arrangement of homeownership. To address this concern and identify the causal effect, we use the IV estimation developed by Lewbel (2012) that exploits the heteroskedasticity as endogenous explanatory variables to construct instrumental variables in the condition of no outside instruments available [31].

The estimations are shown in Table 3, the Hansen statistic demonstrates that instruments conducted from the heteroskedasticity are valid, and coefficients in these two models are robust and consistent, comparing with estimations from the Logit regression.

The results indicate that the homeownership has a positive effect on the establishment of health record (Coefficient $=0.0222 ; 95 \% \mathrm{Cl}=0.0121,0.0323$ ) and the health education access (Coefficient $=0.0241 ; 95 \%$ $\mathrm{Cl}=0.0139,0.0343)$. The results also demonstrate that the predicted probability for homeowners is 2.22 percent higher than the counterpart to establish health record, while the predicted probability of health education participation for homeowners is predicted 2.41 percent exceeding non-homeowners. 


\section{Interaction effect analysis}

The effect of homeownership on the utilization of local public services may depend on the location of household and healthcare center. Therefore, the interaction term of homeownership and household location, together with the interaction term of homeownership and healthcare center location are incorporated into the regressions to address this issue. The results as shown in Table 4 indicate that the interaction term of homeownership and household location(Coefficient $=1.4141 ; 95 \% \mathrm{Cl}=1.2453,1.6057$ ), as well as the interaction between homeownership and healthcare center location (Coefficient=1.1476; $95 \% \mathrm{Cl}=1.0491,1.2554)$ are related with the increased establishment of health records, whereas only the interaction term of homeownership and household location is significantly associated with the increased attendance of health education (Coefficient $=1.2186 ; 95 \% \mathrm{Cl}=1.0734,1.3794$ )

\section{Heterogeneous effect}

The utilization of public health services may be differential by the socioeconomic status. The employed migrants with formal jobs have more likelihood to access public health services [18]. Moreover, rural migrants with longer durations in the destination city would be more familiar with the local society, and they may have more likelihood to access to local public health services [16]. Additionally, intra-provincial migrants also may take more advantages on the public health services access due to the closer distance and acculturation [16].

To address those differentiated traits, we divide the whole sample into several subgroups in term of the employment status, migration duration and migration patterns. Regarding the employment status, we split the sample into employed and unemployed groups. As for the migration duration, we also propose two migrant groups: the short-term duration (duration years $<5$ ) and long-term duration (duration years $>=5$ ). Migration pattern is dichotomized into inter-provincial migration and intra-provincial migration.

The Logit regression is employed to estimate the heterogeneous effects, and the results presented in Table 5 show that the associations across employment status and migration patterns are very similar in the health records model and health education model. The homeownership is associated with the increased local public health services utilization in the employed (health records model:

Coefficient $=0.1737 ; \mathrm{SD}=0.0189$; health education model: Coefficient $=0.1880 ; \mathrm{SD}=0.0186$ ) and unemployed subgroups (health records model: Coefficient $=0.1628 ; S D=0.0365$; health education model: Coefficient $=0.1655 ; S D=0.0362$ ). Meanwhile, some positive correlations between the homeownership and utilization of local public health services are drawn in the inter-provincial group (health records model: Coefficient $=0.2330 \mathrm{SD}=0.0271$; health education model: Coefficient $=0.1619 ; \mathrm{SD}=0.0254$ ) and intraprovincial group (health records model: Coefficient $=0.0852 ; S D=0.0215$; health education model: Coefficient=0.1139; SD=0.0219). Nevertheless, for migration duration differentials, we only got significant relationships among long-term migrants (Coefficient $=0.0864$; $S D=0.0216$ ) and short-term migrants (Coefficient $=0.2457 ; \mathrm{SD}=0.0269$ ) in the prevalence of health record establishment, while only a 
significant association is found among the short-term groups (Coefficient $=0.2972 ; S D=0.0259$ ) in health education model.

\section{Discussion}

The homeownership has a positive effect on the utilization of local public health services among rural migrants, even after correcting the endogeneity of homeownership. The potential mechanism may be as follows: firstly, the homeownership represents great social-economic success in destination [23], and homeowners might share higher social status [32], which would enhance the likelihood to access the local public health services. Secondly, owning a house in the destinations would encourage the social integration of rural migrants [33], and enhance to build more neighborhood cohesion and social capital than comparable renters [34]. Meanwhile, the homeownership is symbolized as a long-term residential stability, which could maintain social ties and decrease stress from residential displacement [35]. Those might be beneficial to utilize the essential public health services [36].

The control variables also have expected impacts (see Table 2). Males are less likely to utilize public health services, which is consistent with previous studies suggesting that females are more sensitive to health problems than males[20][37]. For the socio-economic factors, the higher education attainment is associated with the higher prevalence of health record establishment and health education participation, which is consistent with previous evidences that the level of education is associated with the utilization of public health services[21][38].

The results also reveal that migrants with experience of chronic disease have more likelihood to utilize public health services, which is drawn the consistence that individuals with poorer health status are more likely to seek more health service [15] [20] [39]. It is also confirmed that the permanent settlement intention is related with the increased utilization of public health services, which implies that the stable and long-term residence would encourage seeking behaviors of health services [36].

Apart from the demand-side factors, the supply-side factors, such as the availability and convenience access to public healthcare are also treated as the important determinants [40]. The results demonstrate that migrants living in the urban residential community and spending less time going to the healthcare center are more likely to establish health records and attend in the public health education, which is consistent with the argument that geographical accessibility are of importance to local public health services utilization [15] [30].

The homeownership is usually located in the neighborhoods with better public services, the interaction effect regressions also demonstrate that homeowners living in the urban residential community are more likely to utilize public health services, while rural migrants who own a house in the vicinity of the healthcare center are more prone to access to the public health survives. This implies that the homeownership takes more effect along with the geographical access to health services, while homeowners in the high-quality residential neighborhood may exhibit higher levels of social integration and have more chances to utilize the local public health services. 


\section{Conclusion}

\section{Main findings}

Rural migrants are still detrimental to utilize the basic public health services, the homeownership status may play a vital role in the attainment of local welfare. This study confirms that the homeownership produces a positive effect on the utilization of local public health services among rural migrants in China, while the results also reveal that the homeownership may exert greater effects along with the geographical accessibility.

\section{Limitations}

This study firstly explores the causal effect of homeownership on the utilization of local public health services among rural migrants. Our research has two limitations. One is that the NMPS only has so limited information about the ESS that the current study only discusses two common forms of ESS, whereas more extensive items including public health services for children and elders, immunizations, infectious disease protection and services for patients with type II diabetes should be incorporated in the future studies. Another is that the current study addresses the demand-side and supply-side barriers concurrently, while only conducts discussions on the geographic accessibility due to the data limitation, and other factors like the availability, affordability and acceptability local public health services should be further explored in the future.

\section{Implications}

The homeownership is closely related with the utilization of public health services. Therefore, policymakers should pay more attention to the housing attainment of rural migrants and improve the rural migrant tenants' living conditions. Providing habitable and affordable housing to rural migrants has been raised as the urgent issue for the local government of these urban destinations, thus, expanding the supply of public rental housing should be taken as the major policy directions.

\section{Abbreviations}

NMPDMS: the National Migrants Population Dynamic Monitoring Survey; EPHS :Essential Public Health Services ; OR: Odd Ratio ;Cl: Confidence Interval; IV estimation: Instrument Invariable Estimation ;HC :Healthcare Center

\section{Declarations}

Acknowledgements

None 
ZW took leadership and responsibility for the research activity planning and made substantial contributions to the conception and design of the Programme. JL worked on the statistical analysis of the data. JM drafted the concept of the paper as well as participated in finalizing the manuscript. All authors read and approved the final manuscript.

\section{Funding}

This article is funded by the National Social Science Fund of China (Granted number 17BJY044\&18ZDA081)

\section{Availability of data and material}

The NMPDMS are open and available dataset from the Migrant Population Service Center of National Health Commission, the People's Republic of China (PRC). NMPDMS are however available from the Migrant Population Service Center of National Health Commissio upon reasonable research request. NMPDMS can be requested from the website of Migrant Population Service Center:

http://www.chinaldrk.org.cn/wjw/

\section{Ethics approval and consent to participate}

All data came from public domain. Ethics approval and consent to participate was not applicable.

\section{Consent for Publication}

Not applicable.

\section{Competing interests}

The authors declare that they have no competing interests.

\section{References}

1. Wang, Z., Guo, M., \& Ming, J. (2020). Effect of hometown housing investment on the homeownership of rural migrants in urban destinations: Evidence from China. Cities, 102619.

2. Yang, X. (2004). Temporary migration and the spread of STDs/HIV in China: Is there a link?. International Migration Review, 38(1), 212-235.

3. Sun, M., \& Fan, C. C. (2011). China's permanent and temporary migrants: Differentials and changes, 1990-2000. The Professional Geographer, 63(1), 92-112.

4. Hesketh, T., Jun, Y. X., Lu, L., \& Mei, W. H. (2008). Health status and access to health care of migrant workers in China. Public health reports, 123(2), 189-197.

5. Keung Wong, D. F., Li, C. Y., \& Song, H. X. (2007). Rural migrant workers in urban China: living a marginalised life. International Journal of Social Welfare, 16(1), 32-40. 
6. Mou, J., Griffiths, S. M., Fong, H., \& Dawes, M. G. (2013). Health of China's rural-urban migrants and their families: a review of literature from 2000 to 2012. British medical bulletin, 106(1), 19-43.

7. Zhang, X., Yu, B., He, T., \& Wang, P. (2018). Status and determinants of health services utilization among elderly migrants in China. Global health research and policy, 3(1), 8.

8. Wei, X., Pearson, S., Zhang, Z., Qin, J., Gerein, N., \& Walley, J. (2010). Comparing knowledge and use of health services of migrants from rural and urban areas in Kunming City, China. Journal of biosocial science, 42(6), 743-756.

9. Hong, Y., Li, X., Stanton, B., Lin, D., Fang, X., Rong, M., \& Wang, J. (2006). Too costly to be ill: Health care access and health seeking behaviors among rural-to-urban migrants in China. World health \& population, 8(2), 22-34.

10. Gong, P., Liang, S., Carlton, E. J., Jiang, Q., Wu, J., Wang, L., \& Remais, J. V. (2012). Urbanisation and health in China. The Lancet, 379(9818), 843-852.

11. Wang, L., Wang, Z., Ma, Q., Fang, G., \& Yang, J. (2019). The development and reform of public health in China from 1949 to 2019. Globalization and health, 15(1), 45-55.

12. Yin, D. A model to estimate the cost of the National Essential Public Health Services Package in Beijing, China. BMC Health Services Research. 2015, 1(15): 1-7.

13. Burns, L. R., \& Liu, G. G. (Eds.). (2017). China's healthcare system and reform. Cambridge :Cambridge University Press.

14. Yang, L., Sun, L., Wen, L., Zhang, H., Li, C., Hanson, K., \& Fang, H. (2016). Financing strategies to improve essential public health equalization and its effects in China. International Journal for Equity in Health, 1(15), 1-12.

15. Tian, M.; Wang, H.; Tong, X.T. Essential public health services' accessibility and its determinants among adults with chronic diseases in China. PLoS ONE 2015, 10, e0125262.

16. Qian, Y., Ge, D., Zhang, L., Sun, L., Li, J., \& Zhou, C. (2018). Does Hukou origin affect establishment of health records in migrant inflow communities? A nation-wide empirical study in China. BMC health services research, 18(1), 704.

17. Zhang, D., Pan, X., Li, S., Liang, D., Hou, Z., Li, Y., \& Shi, L. (2018). Impact of the national essential public health services policy on hypertension control in China. American journal of hypertension, 31(1), 115-123.

18. Zhang, J., Lin, S., Liang, D., Qian, Y., Zhang, D., \& Hou, Z. (2017). Public health services utilization and its determinants among internal migrants in China: evidence from a nationally representative survey. International journal of environmental research and public health, 14(9), 1002.

19. Marshall KJ, Urrutia-Rojas X, Mas FS, Coggin C. Health status and access to health care of documented and undocumented immigrant Latino women. Health Care Women International. 2005;26:916-936

20. Lu, L., Zeng, J., \& Zeng, Z. (2017). What limits the utilization of health services among China labor force? Analysis of inequalities in demographic, socio-economic and health status. International journal for equity in health, 16(1), 30.

Page $11 / 15$ 
21. Gong, Y., Yin, X., Wang, Y., Li, Y., Qin, G., Liu, L., ... \& Yang, C. (2014). Social determinants of community health services utilization among the users in China: a 4-year cross-sectional study. PloS one, 9(5), e98095.

22. Alba, R. D., \& Logan, J. R. (1992). Assimilation and stratification in the homeownership patterns of racial and ethnic groups. International migration review, 26(4), 1314-1341.

23. Amuedo-Dorantes, C., \& Mundra, K. (2013). Immigrant homeownership and immigration status: Evidence from Spain. Review of International Economics, 21(2), 204-218.

24. Bramley, G., \& Karley, N. K. (2007). Homeownership, poverty and educational achievement: School effects as neighbourhood effects. Housing Studies, 22(5), 693-721.

25. Holupka, S., \& Newman, S. J. (2012). The effects of homeownership on children's outcomes: Real effects or self-selection?. Real Estate Economics, 40(3), 566-602.

26. Tang, S., Feng, J., \& Li, M. (2017). Housing tenure choices of rural migrants in urban destinations: a case study of Jiangsu Province, China. Housing Studies, 32(3), 361-378.

27. Fang, Y., \& Zhang, Z. (2016). Migrant household homeownership outcomes in large Chinese cities-the sustained impact of hukou. Eurasian Geography and Economics, 57(2), 203-227.

28. Gan, X., Zuo, J., Ye, K., Chang, R., Li, D., \& Zillante, G. (2016). Are migrant workers satisfied with public rental housing?A study in Chongqing, China. Habitat International, 56,96e102.

29. Gan, X., Zuo, J., Chang, R., Li, D., \& Zillante, G. (2016). Exploring the determinants of migrant workers' housing tenure choice towards public rental housing: A case study in Chongqing, China. Habitat International, 58, 118-126.

30. Kiwanuka, S. N., Ekirapa, E. K., Peterson, S., Okui, O., Rahman, M. H., Peters, D., \& Pariyo, G. W. (2008). Access to and utilisation of health services for the poor in Uganda: a systematic review of available evidence. Transactions of the Royal Society of Tropical Medicine and Hygiene, 102(11), 1067-1074.

31. Lewbel, A. (2012). Using heteroscedasticity to identify and estimate mismeasured and endogenous regressor models. Journal of Business \& Economic Statistics, 30(1), 67-80.

32. DeSilva, S., \& Elmelech, Y. (2012). Housing inequality in the United States: Explaining the whiteminority disparities in homeownership. Housing Studies, 27(1), 1-26.

33. Cui, C., Geertman, S., \& Hooimeijer, P. (2016). Access to homeownership in urban China: A comparison between skilled migrants and skilled locals in Nanjing. Cities, 50, 188-196.

34. Rohe, W. M., \& Lindblad, M. (2013). Reexamining the social benefits of homeownership after the housing crisis. Boston: Joint Center for Housing Studies of Harvard University.

35. Lim, S., Stella, S. Y., De La Cruz, N. L., \& Trinh-Shevrin, C. (2017). Defining ethnic enclave and its associations with self-reported health outcomes among Asian American adults in New York City. Journal of immigrant and minority health, 19(1), 138-146.

36. Jing, Z., Wang, Y., Ding, L., Tang, X., Feng, Y., \& Zhou, C. (2019). Effect of social integration on the establishment of health records among elderly migrants in China: a nationwide cross-sectional study. BMJ open, 9(12), 
37. Jankovic J, Simic S, Marinkovic J. Inequalities that hurt: demographic, socioeconomic and health status inequalities in the utilization of health services in Serbia[J]. European Journal of Public Health. 2010;20(4),389-396

38. Shaikh, B. T., \& Hatcher, J. (2005). Health seeking behaviour and health service utilization in Pakistan: challenging the policy makers. Journal of public health, 27(1), 49-54.

39. Anderson, J. G. (1973). Health services utilization: framework and review. Health services research, 8(3), 184-199.

40. Figueroa, J. F., Frakt, A. B., Lyon, Z. M., Zhou, X., \& Jha, A. K. (2017). Characteristics and spending patterns of high cost, non-elderly adults in Massachusetts. Healthcare (Amsterdam, Netherlands), 5(4), 165-170.

\section{Tables}

\begin{tabular}{|c|c|c|c|c|c|c|c|}
\hline & \multirow[t]{2}{*}{ Entire sample } & \multicolumn{2}{|c|}{$\begin{array}{c}\text { Establishment of health } \\
\text { records }\end{array}$} & \multirow[t]{2}{*}{$\chi^{2}$} & \multicolumn{2}{|c|}{ Attendance of health education } & \multirow[t]{2}{*}{$\chi^{2}$} \\
\hline & & $\begin{array}{c}N o \\
\mathrm{~N}(\%) \\
\end{array}$ & $\begin{array}{c}\text { Yes } \\
N(\%) \\
\end{array}$ & & $\begin{array}{c}N o \\
N(\%) \\
\end{array}$ & $\begin{array}{c}\text { Yes } \\
N(\%) \\
\end{array}$ & \\
\hline \multicolumn{8}{|l|}{ Homeownership } \\
\hline No & $109603(82.68)$ & $82357(84.06)$ & $27246(78.78)$ & \multirow[t]{2}{*}{$498.4^{* * *}$} & $44655(86.04)$ & $64948(80.53)$ & \multirow{2}{*}{$670.8^{* * *}$} \\
\hline Yes & $22952(17.32)$ & $15613(15.94)$ & $7339(21.22)$ & & $7245(13.96)$ & $15707(19.47)$ & \\
\hline \multicolumn{8}{|l|}{ Gender } \\
\hline Female & $63639(48.01)$ & $46204(47.16)$ & $17435(50.41)$ & \multirow[t]{2}{*}{$108.2^{* * *}$} & $23180(44.66)$ & $40459(50.16)$ & \multirow[t]{2}{*}{$382.7^{* * *}$} \\
\hline male & $68916(51.99)$ & $51766(52.84)$ & $17150(49.59)$ & & $28720(55.34)$ & 40196(49.84) & \\
\hline Age $^{\text {a }}$ & $36.29 \pm 10.78$ & $36.18 \pm 10.83$ & $36.63 \pm 10.59$ & $24.67^{* * *}$ & $36.55 \pm 11.71$ & $36.13 \pm 10.11$ & $1.4 e+03^{* * *}$ \\
\hline \multicolumn{8}{|l|}{ Marital status } \\
\hline Married & $112455(84.84)$ & $81930(83.63)$ & $30525(88.26)$ & \multirow[t]{2}{*}{$426.5^{* * *}$} & $41704(80.35)$ & 70751(87.72) & \multirow[t]{2}{*}{$1.3 e+03^{* *}$} \\
\hline Single & $20100(15.16)$ & $16040(16.37)$ & $4060(11.74)$ & & $10196(19.65)$ & $9904(12.28)$ & \\
\hline \multicolumn{8}{|l|}{ Education attainment } \\
\hline Primarily & $26547(20.03)$ & $20143(20.56)$ & $6404(18.52)$ & \multirow[t]{4}{*}{$1392.0^{* * *}$} & $11987(23.10)$ & $14560(18.05)$ & \multirow[t]{4}{*}{$644.4^{* * *}$} \\
\hline junior & $64031(48.31)$ & $47481(48.46)$ & $16550(47.85)$ & & $25028(48.22)$ & $39003(48.36)$ & \\
\hline senior & $27273(20.57)$ & $19907(20.32)$ & $7366(21.30)$ & & $9749(18.78)$ & $17524(21.73)$ & \\
\hline college & 14704(11.09) & $10439(10.66)$ & $4265(12.33)$ & & $5136(9.90)$ & $9568(11.86)$ & \\
\hline \multicolumn{8}{|l|}{ Health status } \\
\hline No chronic disease & $125804(94.91)$ & $93148(95.08$ & $32656(94.42)$ & \multirow[t]{2}{*}{$22.73^{* *}$} & 49009(94.43 & $76795(95.21$ & \multirow[t]{2}{*}{$40.21^{* * *}$} \\
\hline Suffered chronic disease & $6751(5.09)$ & $4822(4.92)$ & $1929(5.58)$ & & $2891(5.57)$ & $3860(4.79)$ & \\
\hline \multicolumn{8}{|l|}{ Permanent Settlement Intention } \\
\hline No & $24686(18.62)$ & $19624(20.03)$ & $5062(14.64)$ & \multirow[t]{2}{*}{$490.8^{* * *}$} & $11129(21.44)$ & $13557(16.81)$ & \multirow[t]{2}{*}{$447.6^{* * *}$} \\
\hline Yes & $107869(81.38)$ & $78346(79.97)$ & $29523(85.36)$ & & $40771(78.56)$ & $67098(83.19)$ & \\
\hline \multicolumn{8}{|l|}{ Household location } \\
\hline Village & $39608(29.88)$ & $30883(31.52)$ & $8725(25.23)$ & \multirow[t]{2}{*}{$483.5^{* * *}$} & $18052(34.78)$ & $21556(36.73)$ & \multirow[t]{2}{*}{$978.2^{* * *}$} \\
\hline Urban residential community & $92947(70.12)$ & $67087(68.48)$ & $25860(74.77)$ & & $33848(65.22)$ & $59099(73.27)$ & \\
\hline \multicolumn{8}{|l|}{ Healthcare center(HC) location } \\
\hline Distance to the nearest $\mathrm{HC}$ more than 15 minutes & $21984(16.58)$ & $16933(17.28)$ & $5051(14.60)$ & \multirow[t]{2}{*}{$132.7^{* * *}$} & 9054(17.44) & $12930(16.03)$ & \multirow[t]{2}{*}{$45.63^{* * *}$} \\
\hline Distance to the nearest $\mathrm{HC}$ less than 15 minutes & $110571(83.42)$ & $81037(82.72)$ & $29534(85.40)$ & & $42846(82.56)$ & $67725(83.97)$ & \\
\hline$n$ & 132555 & $97970(73.91)$ & $34585(26.09)$ & & $51900(39.15)$ & $80655(60.85)$ & \\
\hline
\end{tabular}

Table 2 Association between homeownership and utilization of local public health services: Multivariate logit

Table 3 Causal effects of homeownership on utilization of local public health services 
Homeownership

Gender (female=1)

Age

Marital status(married=1)

Junior middle school(ref: Primarily school or below)

Senior middle school (ref: Primarily school or below)

College or above(ref: Primarily school or below)

Health status (Chronic disease $=1$ )

Permanent settlement intention

Household location (urban residential community=1)

Healthcare center $(\mathrm{HC})$ location (distance to the nearest HC less

than 15 minutes=1)

constant

\begin{tabular}{ccc|clc}
\multicolumn{3}{c}{ Health record } & & \multicolumn{3}{c}{ Health education } \\
\hline OR & CI (95\%) & $\begin{array}{c}\text { p- } \\
\text { value }\end{array}$ & OR & CI (95\%) & $\begin{array}{c}\text { p- } \\
\text { value }\end{array}$ \\
\hline 1.1926 & $(1.1540$, & 0.0000 & 1.1883 & $(1.1506,1.2271)$ & 0.0000 \\
1.1390 & $(1.1107,1.1682)$ & 0.0000 & 1.2112 & $(1.1837$, & 0.0000 \\
1.0027 & $(1.0013,1.0042)$ & 0.0000 & 0.9926 & $(0.9913,0.9940)$ & 0.0000 \\
1.4199 & $(1.3623,1.4798)$ & 0.0000 & 2.0475 & $(1.9760,2.1217)$ & 0.0000 \\
1.1321 & $(1.0925,1.1732)$ & 0.0000 & 1.2606 & $(1.2219,1.3005)$ & 0.0000 \\
1.2085 & $(1.1578,1.2614)$ & 0.0000 & 1.4693 & $(1.4138,1.5270)$ & 0.0000 \\
1.3241 & $(1.2579,1.3938)$ & 0.0000 & 1.5065 & $(1.4372,1.5792)$ & 0.0000 \\
1.1101 & $(1.0484,1.1754)$ & 0.0000 & 0.9297 & $(0.8822,0.9798)$ & 0.0060 \\
1.3617 & $(1.3160,1.4090)$ & 0.0000 & 1.2203 & $(1.1859,1.2558)$ & 0.0000 \\
1.2694 & $(1.2330,1.3068)$ & 0.0000 & 1.3608 & $(1.3271$, & 0.0000 \\
1.1898 & $(1.1494,1.2315)$ & 0.0000 & 1.0571 & $(1.0257,1.0895)$ & 0.0000 \\
0.2169 & $(0.2000,0.2352)$ & 0.0000 & 1.7368 & $(1.6153,1.8675)$ & 0.0000 \\
\hline
\end{tabular}

\begin{tabular}{|c|c|c|c|c|c|c|}
\hline & \multicolumn{6}{|c|}{ Instrumental variables estimation using heteroskedasticity-based instruments } \\
\hline & \multicolumn{3}{|c|}{ Health record } & \multicolumn{3}{|c|}{ Health education } \\
\hline & Coefficients & CI $(95 \%)$ & $\begin{array}{c}\mathrm{p}- \\
\text { value }\end{array}$ & Coefficients & CI $(95 \%)$ & $\begin{array}{l}\mathrm{p}- \\
\text { value }\end{array}$ \\
\hline Homeownership & 0.0222 & $(0.0121,0.0323)$ & 0.000 & 0.0241 & $(0.0139,0.0343)$ & 0.000 \\
\hline Constant & 0.1756 & $(0.1607,0.1905)$ & 0.00 & 0.6308 & $(0.6138,0.6478)$ & 0.000 \\
\hline Controls & & YES & & & YES & \\
\hline $\begin{array}{l}\text { Cragg-Donald Wald F statistic(5\% maximal IV relative bias } \\
20.74 \text { ) }\end{array}$ & & 12000 & & & 12000 & \\
\hline \multirow[t]{4}{*}{ Hansen J statistic (p) } & & 0.1516 & & & 0.3048 & \\
\hline & \multicolumn{6}{|c|}{ Marginal effect(Logit) } \\
\hline & \multicolumn{3}{|c|}{ Health record (ME) } & \multicolumn{3}{|c|}{ Health education(ME) } \\
\hline & Coefficients & CI (95\%) & $\begin{array}{c}\mathrm{p}- \\
\text { value }\end{array}$ & Coefficients & CI (95\%) & $\begin{array}{r}\mathrm{p}- \\
\text { value }\end{array}$ \\
\hline $\begin{array}{l}\text { Homeownership } \\
\text { Controls }\end{array}$ & 0.0335 & $\begin{array}{l}(0.0272,0.0398) \\
\text { YES }\end{array}$ & 0.000 & 0.0398 & $\begin{array}{l}(0.0324,0.0472) \\
\text { YES }\end{array}$ & 0.000 \\
\hline
\end{tabular}

Table 4 Homeownership, location of household and healthcare center(HC), and utilization of local public health services: interaction effect

\begin{tabular}{|c|c|c|c|c|c|c|}
\hline & \multicolumn{6}{|c|}{ Instrumental variables estimation using heteroskedasticity-based instruments } \\
\hline & \multicolumn{3}{|c|}{ health records } & \multicolumn{3}{|c|}{ Health education } \\
\hline & Coefficients & CI $(95 \%)$ & $\begin{array}{c}\mathrm{p}- \\
\text { value }\end{array}$ & Coefficients & CI $(95 \%)$ & $\begin{array}{l}\mathrm{p}- \\
\text { value }\end{array}$ \\
\hline Homeownership*Urban residential community & 1.4141 & $(1.2453,1.6057)$ & 0.0000 & 1.2168 & $(1.0734,1.3794)$ & 0.0020 \\
\hline $\begin{array}{l}\text { Homeownership* Distance to the nearest HC less than } 15 \\
\text { minutes }\end{array}$ & 1.1476 & $(1.0491,1.2554)$ & 0.0030 & 1.0761 & $(0.9892,1.1708)$ & 0.0880 \\
\hline Homeownership & 1.0358 & $(0.9520,1.1271)$ & 0.4140 & 1.1015 & $(1.0182,1.1917)$ & 0.0160 \\
\hline Urban residential community & 1.2928 & $\begin{array}{l}(1.2549 \\
1.3319)\end{array}$ & 0.0000 & 1.0761 & $(0.9892,1.1708)$ & 0.0000 \\
\hline Distance to the nearest $\mathrm{HC}$ less than 15 minutes & 1.1589 & $(1.1157,1.2038)$ & 0.0000 & 1.0451 & $(1.0115,1.0798)$ & 0.0080 \\
\hline Constant & 0.2227 & $(0.2052,0.2418)$ & 0.0000 & 1.7575 & $(1.6334,1.8911)$ & 0.0000 \\
\hline Controls & \multicolumn{3}{|c|}{ YES } & \multicolumn{3}{|c|}{ YES } \\
\hline
\end{tabular}

Notes: Control variables include gender, age ,and marital status, education attainment, health status and permanent settlement intention .

Table 5 Homeownership and utilization of local public health services: heterogeneous effect 


\begin{tabular}{|c|c|c|c|c|c|c|}
\hline & \multicolumn{6}{|c|}{ Health record } \\
\hline & \multicolumn{2}{|c|}{ Employment Status } & \multicolumn{2}{|c|}{ Migration Duration } & \multicolumn{2}{|c|}{ Migration Patterns } \\
\hline & Employed & Unemployed & Duration $>=5$ & Duration $<5$ & Inter-provincial & Intra-provincial \\
\hline Homeownership & $\begin{array}{c}0.1737^{* * *} \\
(0.0189)\end{array}$ & $\begin{array}{c}0.1628^{* * *} \\
(0.0365)\end{array}$ & $\begin{array}{c}0.0864^{* * *} \\
(0.0216)\end{array}$ & $\begin{array}{c}0.2457^{* * *} \\
(0.0269)\end{array}$ & $\begin{array}{c}0.2330^{* * *} \\
(0.0271)\end{array}$ & $\begin{array}{c}0.0852^{* * *} \\
(0.0215)\end{array}$ \\
\hline Constant & $\begin{array}{c}-1.5927^{* * *} \\
(0.0480)\end{array}$ & $\begin{array}{c}-1.4064^{* * *} \\
(0.0861)\end{array}$ & $\begin{array}{c}-1.2466^{* * *} \\
(0.0576)\end{array}$ & $\begin{array}{c}-1.6273^{* * *} \\
(0.0625)\end{array}$ & $\begin{array}{c}-1.5958^{* * *} \\
(0.0611)\end{array}$ & $\begin{array}{c}-1.4216^{* * *} \\
(0.0572)\end{array}$ \\
\hline \multirow[t]{4}{*}{$N$} & $\begin{array}{c}\text { Yes } \\
110009 \\
\end{array}$ & $\begin{array}{c}\text { Yes } \\
22546 \\
\end{array}$ & $\begin{array}{c}\text { Yes } \\
65788 \\
\end{array}$ & $\begin{array}{c}\text { Yes } \\
66767 \\
\end{array}$ & $\begin{array}{c}\text { Yes } \\
67680 \\
\end{array}$ & $\begin{array}{c}\text { Yes } \\
64875 \\
\end{array}$ \\
\hline & \multicolumn{6}{|c|}{ Health Education } \\
\hline & \multicolumn{2}{|c|}{ Employment Status } & \multicolumn{2}{|c|}{ Migration Duration } & \multicolumn{2}{|c|}{ Migration Patterns } \\
\hline & Employed & Unemployed & Duration $>=5$ & Duration $<5$ & Inter-provincial & Intra-provincial \\
\hline Homeownership & $\begin{array}{c}0.1880^{* * *} \\
(0.0186)\end{array}$ & $\begin{array}{c}0.1655^{* * *} \\
(0.0362)\end{array}$ & $\begin{array}{c}-0.0242 \\
(0.0218)\end{array}$ & $\begin{array}{c}0.2972^{* * *} \\
(0.0259)\end{array}$ & $\begin{array}{c}0.1619^{* * *} \\
(0.0254)\end{array}$ & $\begin{array}{c}0.1139^{* * *} \\
(0.0219)\end{array}$ \\
\hline Constant & $\begin{array}{c}0.4244^{* * *} \\
(0.0421)\end{array}$ & $\begin{array}{c}0.8187^{* * *} \\
(0.0777)\end{array}$ & $\begin{array}{c}1.2185^{* * *} \\
(0.0544)\end{array}$ & $\begin{array}{c}0.3398^{* * *} \\
(0.0518)\end{array}$ & $\begin{array}{c}0.4063^{* * *} \\
(0.0505)\end{array}$ & $\begin{array}{c}0.7468^{* * *} \\
(0.0539)\end{array}$ \\
\hline $\begin{array}{l}\text { Controls } \\
N\end{array}$ & $\begin{array}{c}\text { Yes } \\
110009\end{array}$ & $\begin{array}{c}\text { Yes } \\
22546\end{array}$ & $\begin{array}{c}\text { Yes } \\
65788\end{array}$ & $\begin{array}{c}\text { Yes } \\
66767\end{array}$ & $\begin{array}{c}\text { Yes } \\
67680\end{array}$ & $\begin{array}{c}\text { Yes } \\
64875\end{array}$ \\
\hline
\end{tabular}

Notes: ${ }^{* * *}$ significant ( $\leq$ 0.01); Control variables include gender, age , and marital status, education attainment, health status , permanent settlement intention ,household location and healthcare center location. 